\title{
La fin de territoires. Essai sur le désordre international et sur l'utilité social du respect
}

Bertrand Badie

Reseña escrita por Jesús Alberto Suárez Pineda *

* PhD (c) en Estudios Políticos, Universidad Externado de Colombia.

Paris: Fayard, Collection l'espace du politique, 1995, 276 p.; 15,4 cm $\times 23,5 \mathrm{~cm} \times 2,1 \mathrm{~cm}$ : incluye bibliografía. Idioma: francés. ISBN: 2-213-59460-0.

Contenido. Una invención entre otras / Una larga historia / El lento ascenso del principio de territorialidad / El orden territorial rige el mundo / Crisis múltiples / Culturas del espacio / La paradoja identitaria / La descomposición de los territorios / Más allá del territorio / Algunos falsos desplazamientos / De la recomposición.

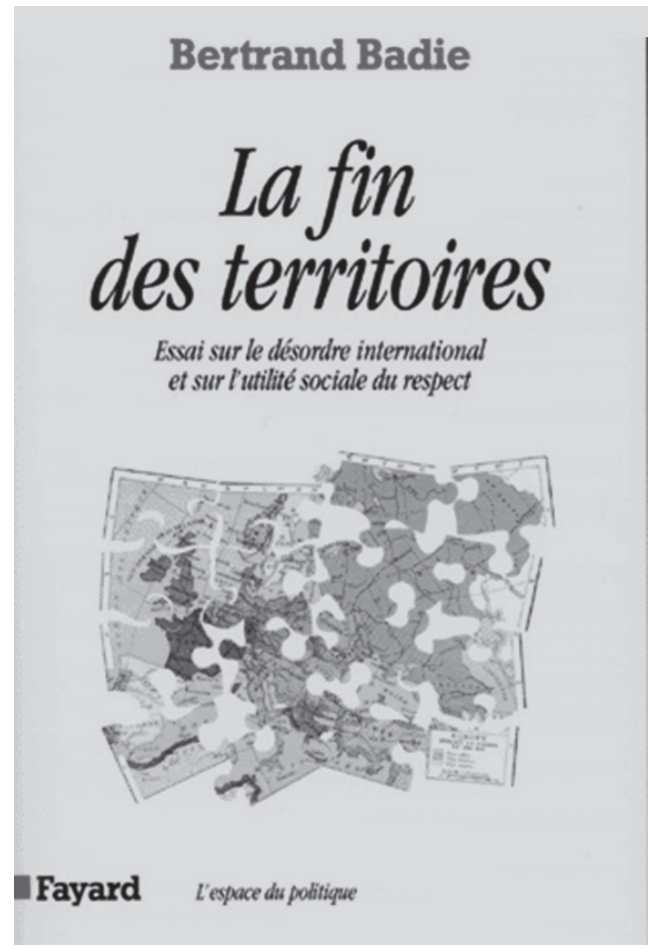

Resumen. El autor presenta la emergencia del territorio como concepto político (las ciudades griegas, los imperios, el feudalismo no funcionan según nuestra idea de correspondencia absoluta entre espacio de producción de lo práctico y territorio), su universalización progresiva, su hegemonía afirmada, en particular por la colonización y luego descolonización que han podido respetar los modos locales de organización de lo político. Lo que es artificial en África, comenta Bertrand Badie, no es el trazado de fronteras, sino el sentido que reviste, en contra de las solida- 
ridades constitutivas de un político particular. En la segunda parte, el autor analiza las crisis que sacuden el principio de territorialidad desde mediados los años sesenta. En la última parte estudia los modos de regulación posible de esta crisis del territorio. En efecto, el territorio no ha representado nunca todos los espacios de lo político, e incluso cuando el discurso político aparenta hablar de geografía no habla necesariamente de territorio: cuando los israelitas evocan la tierra de Israel, ¿hablan de un territorio, de un espacio heredado, de cultura? Parece incluso que bajo la apariencia de un Estado homogéneo, territorialmente definido (Somalia, por ejemplo), perduran otras lógicas lo suficientemente arraigadas para impedir el funcionamiento de instituciones estatales. Dicho en otras palabras, casi en todo, y sin duda cada vez más, se oponen a la lógica del territorio (contorno y límites de lo político en nuestra concepción occidental), y especialmente en la lógica de una política pensada a través de múltiples espacios, de múltiples identidades, no reducibles a la geografía territorial.

Materia geográfica. Bertrand Badie; Territorio; Territorialidad; Sistema internacional; Relaciones internacionales; desorden internacional.

Presentación del libro. El tema del "fin de los territorios" (nacionales) o de una "territorialidad fallida" es desarrollado por el autor en su libro La fin des territoires. Essai sur le désordre international et sur l'utilité sociale du respect ("El fin de los territorios. Ensayo sobre el desorden internacional y sobre la utilidad social del respeto").

La tesis central del autor plantea que la relación entre soberanía y seguridad del sistema internacional, en la segunda mitad del siglo xx, depende en gran medida de la relación entre Estado y sociedad. El Estado se ha vuelto más tolerante en cuanto al hecho de consultar y reconocer que no es el actor unitario en materia de soberanía ni de seguridad, sino que la sociedad civil desempeña un papel fundamental, ya que con ella trata de construir una serie de consensos. El Estado tiene que compartir con otros actores cuando empiezan a coger fuerza las redes sociales en Internet.

De este modo, la autoridad política descansa en derechos que residen en los ciudadanos como personas, antes que en virtud de su pertenencia a un territorio (p. 31). La relación de obediencia se deriva aquí de la obligación de fidelidad, de naturaleza jurídica y moral. Al apoyarse en vínculos de lealtad personal, el orden político está, en esencia, disociado del principio de territorialidad. Desde el punto de vista del autor, es preciso identificar un principio moderno de territorialidad, pues el territorio ha sido siempre una producción social cuya ocupación y ordenamiento son el resultado de una lucha permanente entre grupos sociales. El triunfo de la territorialidad tradicional se vuelve contra ella.

Este fenómeno no concierne exclusivamente al África negra, aunque parece más amenazante en esta región del mundo ante el hecho de la génesis reciente del Estado y del difícil enraizamiento de los conceptos importados de nación y ciudadanía (p. 254). Tayikistán, por ejemplo, invención de Stalin, no correspondía ni a una identidad ni a un territorio histórica y culturalmente bien definidos. "Hemos pensado", nos dice Bertrand Badie, "que el territorio era un tema, una categoría 'animal' y universal, dado que, en sus relaciones con lo político, es una construcción, intelectual e histórica, algo que se puede describir". Para el autor,

[...] el principio de territorialidad presupone que el territorio sea reconocido como forma de constitución de un orden, como un principio que estructura las comunidades políticas, sin que dicho principio se derive de alguna solidaridad social que le sea anterior, que sea distinto de 
él, o que lo trascienda. Cualquier otra distribución convertiría el orden territorial en una aporía, puesto que le restaría su función discriminatoria en la definición de las competencias jurisdiccionales (p. 47).

Si se sigue el desarrollo de esta reflexión, la aporía ${ }^{1}$ de la que habla Badie se entiende en el sentido de 'dificultad de orden racional que parece no tener salida', y que luego él conceptualiza como aporía territorial (véase p. 89). Esto implica el fin del enfoque clásico de las relaciones internacionales sobre el territorio, donde cada Estado regulaba soberanamente el funcionamiento de su dinámica socioeconómica en sus fronteras, en un mundo gobernado por el principio de territorialidad.

Por lo demás, también está cambiando el mismo concepto de soberanía sobre el territorio, orden que aparece en Europa luego de la Guerra de los Treinta Ańos y la paz de Westfalia. Esto ha tenido un gran efecto en el ámbito político, ya que la distancia ha dejado de ser, como lo había sido durante siglos, un recurso del gobierno. La autoridad del Estado-nación se basaba en parte en esa distancia, ya que daba un sentido al territorio nacional. Pero este sistema ya no funciona con los fenómenos de regionalización y globalización que están poniendo en tela de juicio el concepto mismo de Estado-nación, ${ }^{2}$ pues este ya no representa la relación constitutiva entre la comunidad y el territorio. En este sentido, el territorio no es una realidad natural sino una construcción social dotada de historicidad.

Tanto la historia antigua como la reciente nos muestra bien hasta qué punto las categorías de identidad son efectivamente cambiantes, "volátiles" y dependientes tanto de interacciones entre los Estados, los actores regionales y locales, como de las instancias internacionales insertas en contextos políticos y económicos globalizadores. La nueva racionalidad territorial evidencia que la confusión de prácticamente todos los interesados entre identidad y territorio es en sí misma fuente de violencia potencial.

En momentos de internacionalización de la economía y de la modernización de las técnicas de comunicación, Badie evoca la crisis de los territorios nacionales, y subraya el carácter inadecuado y obsoleto de los Estados-nacionales, a finales del siglo xx, los cuales en todas partes han sido objeto de ataques violentos, por presión de movimientos identitarios fundados en una misma adhesión étnica, religiosa o cultural, o por el ascenso de redes económicas transnacionales y de modelos económicos regionales. Todo esto es constatado por movimientos de población y empresas de todas partes del mundo, lo que se ha traducido en la actual crisis del Estado-nación y el declive de la soberanía.

Según Badie, la modernización es la expansión de lo transnacional, producto del ascenso de redes transnacionales; deforma los Estados-naciones, resquebraja su soberanía, ignora sus fronteras y trasciende sus particularidades, sin importar la naturaleza de los flujos económico, financiero y comercial, sin importar los flujos mafiosos, los ligados a todas las prácticas delincuenciales de la violencia, o que incluso se trata de flujos culturales, migratorios, y de la desterritorialización que

\footnotetext{
1 Procedente del griego aporía (de $a$-, sin, y poros, salida), este término significa, en sentido propio, dificultad para salir; en sentido figurado, duda, problema sin solución.

2 Sistema político singular inventado en Europa occidental, que tardó seis siglos (del siglo XIII al XIX) en afirmarse en todo el continente y que se ha constituido en fundamento de las relaciones internacionales y principal marco de referencia de la soberanía y de la democracia de las comunidades humanas contemporáneas.
} 
se deriva de ello. Como consecuencia de esta crisis, la irrupción de las relaciones transnacionales constata la creciente porosidad de las fronteras, el declive de la soberanía y el complejo juego de las relaciones entre lo externo y lo interno. El déficit de las regulaciones supranacionales y el desarrollo de comunidades étnicas anuncian el fin de los territorios nacionales, en el sentido de que estos movimientos sociales se están reorganizando en el escenario mundial con una evidente emancipación de la administración territorial, lo que a su vez implica el fin de una manera exclusiva de regulación: el Estado deja de ser el único actor organizador o regulador del espacio político (p. 11). Nuestra escena mundial se mundializa precisamente porque no está irrigada por todo un ensamblaje de relaciones que tienen su fuerza propia.

Si estas redes transnacionales tienen la capacidad y el desempeńo que nosotros les atribuimos, es porque se encuentran alimentadas por el desconocimiento de las fronteras de los Estadonación, porque precisamente estas redes se alimentan de esas fronteras para reforzarse y pasar por alto aún más abiertamente las lógicas de la soberanía territorial.

En conclusión, ha nacido una forma generatriz y movilizadora de conflictos. Es así como para Badie lo que caracteriza la globalización es menos la ruptura con un conjunto de configuraciones territoriales, que un pasaje al límite que conduce a poner en entredicho un orden territorial mundial, dominado por el pensamiento político después de los tratados de Westfalia.

La globalización no es, como suele decirse, un fenómeno principalmente económico: su origen es una importantísima revolución técnica, que implica la abolición de la distancia, con la aparición de unas redes de comunicación, financieras y humanas, cuya caracterización implica una nueva "gramática del espacio", producto de la irrupción de unas relaciones transnacionales que se establecen entre individuos más allá de las fronteras y por encima del control de los Estados.

\section{Crítica}

El título del libro es realmente provocador. Sin embargo, más que "el fin de los territorios" — los títulos tienen sus propias traiciones-, el texto de Bertrand Badie nos describe la relatividad del territorio para los pueblos cuya cultura política es la de un Estado unitario, y cuya cultura estratégica se ha organizado en los países europeos durante poco más de tres siglos, en torno a la defensa del territorio y de su proyección, a partir de un territorio definido. De ahí provienen las dificultades de algunos Estados modernos, para definir su propio poder y su política exterior.

El subtítulo (Ensayo sobre el desorden internacional y sobre la utilidad social del respeto) le sugiere al lector dos horizontes de significación: por un lado, la decadencia del enfoque realista de las relaciones internacionales, según el cual los Estados wesfalianos se caracterizan por la oposición entre un orden nacional (cuya soberanía y territorio es objeto de una seguridad militar) y el desorden internacional (en el que todo vale en defensa de intereses particulares) y, por el otro, se plantea la utilidad social del "respecto" (en el sentido etimológico del verbo latino respicere de "mirar al otro"), es decir, no pasar por encima del otro (un país, una nación), de reconocerlo, en las mutaciones del sistema internacional, que están conduciendo al fin de los territorios nacionales, en virtud del recrudecimiento de los fundamentalismos religiosos, el retorno de las reivindicaciones culturales y el surgimiento de una sociedad red. 
Entre los internacionalistas actuales hoy tiene mucha fuerza la idea contemporánea del fin de los territorios y de las fronteras en un mundo donde se multiplican los flujos financieros, de mercados y de información, en el que la Internet ha abolido las distancias. ${ }^{3}$ Sin embargo, esto no quiere decir que la geografía y el espacio ya no cuenten. Si el territorio, como lo concebimos políticamente, tiene un nacimiento y un desarrollo, puede también conocer una crisis, que Bertrand Badie describe por cierto con gran lujo de detalles.

La obra se concentra en la crítica de algunas tendencias actuales, erigidas muy rápidamente en modelos de transición del orden Estado-territorial: los mercados globales, la integración en virtud de organizaciones transnacionales y sus calcos regionales. El autor evoca entonces un tríptico susceptible de contribuir a la combinación de lógicas territoriales (remanentes, con el poder de los Estados) y lógicas de espacios (cada vez más afianzadas): el manejo paralelo de un "regionalismo concebido a escala mundial", de "temas solidarios" que activan las independencias, de una idea de "pluralismo estructurado", que tendría el sentido de una redefinición consensual de "la función de hitos limítrofes y fronteras".

Ahora bien: como las mejores ideas, la de territorio puede revocarse, transformarse, perder sentido. El fracaso evidenciado de un territorio que pretende trascender la oposición de los espacios políticos comunitarios va a ser reivindicado por estas mismas comunidades, al contrario de su lógica universal. Es este precisamente el fondo de los acontecimientos de la ex Yugoslavia. La reivindicación del Estado, del territorio, no sirve ya para sintetizar, por la invención de un nivel superior de creación política, las identidades contradictorias de agrupamientos humanos que deciden convivir. Esta reivindicación sirve para proclamarse contra su propia identidad, contra su otro tú, irreducible, de donde proviene la limpieza étnica.

En fin, no sabemos bien que incluso en los Estados que "están en marcha" el proceso de globalización plantea de una manera nueva la cuestión de la soberanía, del lugar de la decisión y, por ende, del territorio contemplado por la decisión política. El territorio agoniza, repite Bertrand Badie, porque no es más que el lugar de la soberanía, porque las estrategias que propenden a garantizar la seguridad ya no se definen solamente ni incluso antes que nada, en relación con el territorio, puesto que los enfrentamientos bélicos se organizan cada vez menos en torno a meras pretensiones territoriales. El enigma de la definición del territorio europeo es aquí emblemático: ¿cómo la Unión Europea, sujeto político a la vez unificado y diverso, va a conceptualizar su necesaria territorialización?

Las comunidades nacionales, las comunidades de soberanía, han dado paso a la comunidad de responsabilidad, que para el caso de la Unión Europea "significa cooperación para evitar y arbitrar los conflictos en el ámbito de la política exterior y de seguridad. Pero también conlleva desde el punto de vista político-comercial y ecológico, un comercio altruista y en regla respecto a las otras regiones mundiales" (Carta sobre la identidad europea).

3 El autor también desarrolla esta idea en Bertrand Badie, Marie-Claude Smouts, Le Retournement du monde. Sociologie de la scène internationale, Paris, Presses de Sciences Po et Dalloz, 3e éd. 1999; Bertrand Badie, Marie-Claude Smouts (dir.), L'International sans territoire, Paris, L'Harmattan, 1996 (Cultures \& Conflits). En relación con el tema de la soberanía, ver su obra Un monde sans souveraineté. Les états entre ruse et responsabilité, Fayard, 1999 (trad. esp. Un mundo sin soberanía. Estados entre artificio y responsabilidad, Universidad Externado de Colombia-TM Editores, 2000). 
Así pues, se crean nuevas formas de regionalismo sobre una base económica: regiones transnacionales que unen entre sí partes de diversos Estados a través de dinámicas productivas y de mercado, deshaciendo la unidad de los territorios estatales, también a pesar de las importantes diferencias culturales, e incluso de las antiguas y rígidas contraposiciones políticas que caracterizan los Estados de las zonas en cuestión, como demuestra el caso del sudeste asiático. Puestas en juego de otra naturaleza (social, cultural, política) crean otras comunidades de responsabilidad y alimentan otras formas de regionalismo. Según Ohmae (1995, pp. 128 ss.), emergen los Estadosregiones, esto es, una entidad territorial que a veces están totalmente dentro de las fronteras de un solo Estado (o coinciden con ellas: es el caso de una ciudad-Estado como Singapur) y a veces las traspasan o las dividen, englobando parte de otros Estados: son sus funciones económicas para administrar los intereses, las exigencias y las opciones con que realmente cuentan. También las líneas de demarcación territorial con que cuentan realmente incluso ya no serían la de los Estadosnaciones sino la de los Estados-regiones (K. Ohmae, 1995, pp. 128 ss.).

\section{Bibliografía}

1. Badie, B. (1995). La fin de territoires. Essai sur le désordre internationale et sur l'utilité social du respect. París: Fayard.

2. Badie, B. (1997). L'aporia territoriale, Geotema, 3(9), 22-24.

3. Ohmae, K. (1995): The End of the Nation State. Nueva York: Free Press. 